\title{
Winkler model for axially loaded piles in inhomogeneous soil
}

\author{
J. J. CRISPIN*, C. P. LEAHY† and G. MYLONAKIS\$\$ף
}

\begin{abstract}
Analytical closed-form solutions are developed for the elastic and elasto-plastic settlement of axially loaded piles in inhomogeneous soil. The soil is modelled by way of a bed of Winkler (' $t-z$ ') springs with stiffness varying as a power function of depth, described by two dimensionless inhomogeneity parameters. The associated governing differential equation is solved in an exact manner using Bessel functions, which reproduce the solution for homogeneous soil. Additional limiting cases are explored including: (a) infinitely long piles, (b) short piles, (c) perfectly floating piles and (d) perfectly end-bearing piles. The solution is extended to the non-linear range by employing elastic-perfectly plastic Winkler springs. A systematic approach for predicting the full load-settlement curve is presented and applied to tests from a site in London. Dimensionless charts are provided for routine design.
\end{abstract}

KEYWORDS: piles \& piling; settlement; soil/structure interaction

Published with permission by the ICE under the CC-BY 4.0 license. (http://creativecommons.org/licenses/by/4.0/)

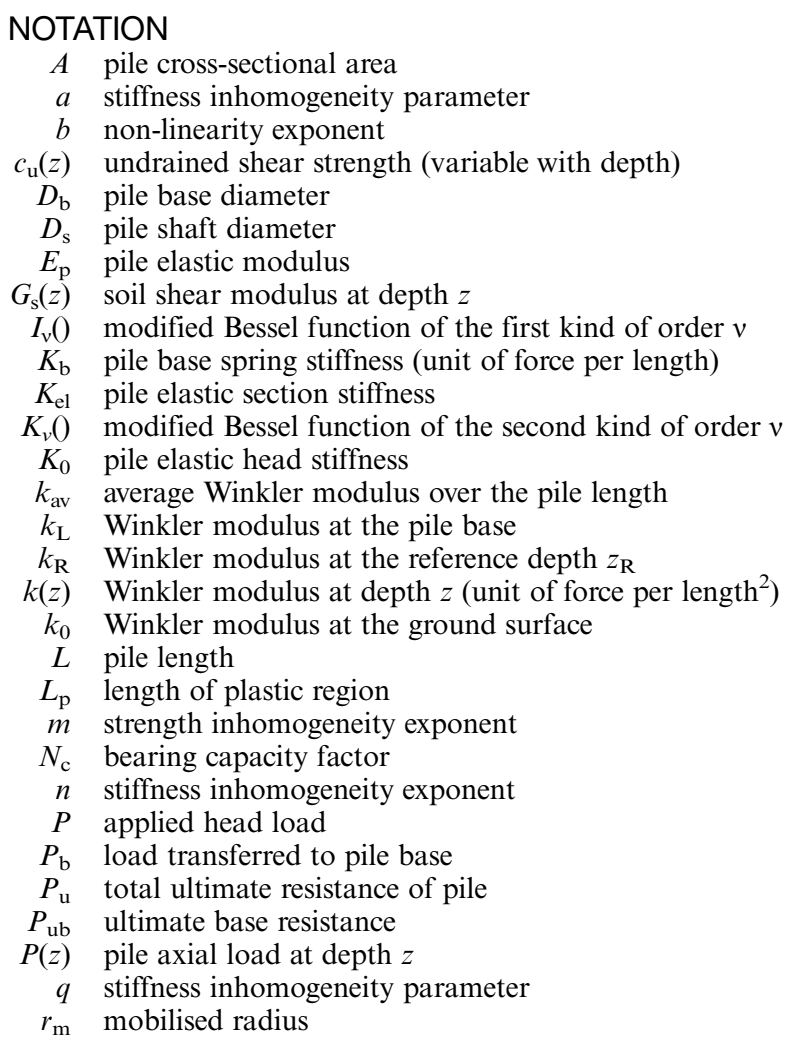

Manuscript received 17 April 2018; first decision 17 October 2018; accepted 22 October 2018.

Published online at www.geotechniqueletters.com on 17 December 2018.

*Department of Civil Engineering, University of Bristol, Bristol, UK (Orcid:0000-0003-3074-8493).

$\dagger$ Jacobs UK Ltd, London, UK (Orcid:0000-0002-3826-0233).

tDepartment of Civil Engineering, University of Bristol, Bristol, UK (Orcid:0000-0002-8455-8946).

§Department of Civil Engineering, University of Patras, Rio, Greece.

-Department of Civil and Environmental Engineering, University of California, Los Angeles, USA.

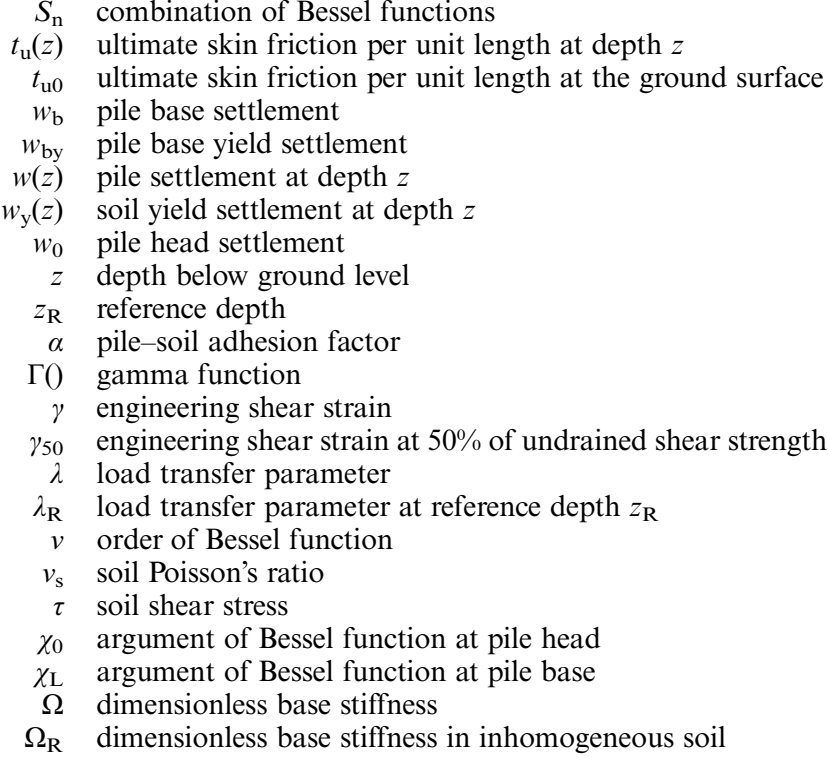

\section{INTRODUCTION}

The Winkler model and related load-transfer analyses have been used extensively to model piles under axial load (e.g. Randolph \& Wroth, 1978; Poulos \& Davis, 1980; Scott, 1981; Mylonakis \& Gazetas, 1998; Salgado, 2008; Guo, 2012). With careful selection of the Winkler modulus, the model has been shown to agree well with more rigorous continuum analyses (Mylonakis, 2001a, 2001b; Syngros, 2004; Guo, 2012; Anoyatis, 2013; Anoyatis et al., 2018). Scott (1981) and Guo (2012) extended the Winkler model to inhomogeneous soil and provided closed-form solutions for pile head stiffness when soil stiffness varies as a power function of depth. This paper considers a similar stiffness variation to investigate the necessity of considering soil inhomogeneity when predicting pile settlement. New solutions are provided for the limiting cases of pile length, base conditions and soil inhomogeneity. The method is extended to the non-linear range by employing elastic-perfectly plastic Winkler springs, and applied to predict complete load-settlement curves for a series of tests on a site in London. 


\section{LINEAR RESPONSE}

The pile model considered is depicted in Fig. 1. The base resistance is represented by a spring with stiffness $K_{\mathrm{b}}$ and shaft resistance by uniformly distributed Winkler springs of stiffness $k(z)$. The equilibrium of an arbitrary section of the pile yields the familiar governing differential equation (Scott, 1981)

$$
E_{\mathrm{p}} A w^{\prime \prime}(z)-k(z) w(z)=0
$$

dimensionless coefficient accounting for non-zero surface stiffness and $n$ a positive inhomogeneity exponent.

A simple approach to account for soil inhomogeneity is to calculate an average Winkler modulus, $k=k_{\mathrm{av}}$, over the whole pile length and use equation (2) to obtain the pile stiffness treating the soil as a homogeneous medium. To assess the validity of this approximation, one may compare against the exact solution to equations (1) and (4), given by equation 5

$$
K_{0}=E_{\mathrm{p}} A \lambda_{\mathrm{R}} a^{n / 2} \frac{q^{n / 2}\left[I_{v-1}\left(\chi_{0}\right) I_{1-v}\left(\chi_{\mathrm{L}}\right)-I_{1-v}\left(\chi_{0}\right) I_{v-1}\left(\chi_{\mathrm{L}}\right)\right]+\Omega_{\mathrm{R}}\left[I_{v-1}\left(\chi_{0}\right) I_{-v}\left(\chi_{\mathrm{L}}\right)-I_{1-v}\left(\chi_{0}\right) I_{+v}\left(\chi_{\mathrm{L}}\right)\right]}{q^{n / 2}\left[I_{-v}\left(\chi_{0}\right) I_{v-1}\left(\chi_{\mathrm{L}}\right)-I_{+v}\left(\chi_{0}\right) I_{1-v}\left(\chi_{\mathrm{L}}\right)\right]+\Omega_{\mathrm{R}}\left[I_{-v}\left(\chi_{0}\right) I_{+v}\left(\chi_{\mathrm{L}}\right)-I_{+v}\left(\chi_{0}\right) I_{-v}\left(\chi_{\mathrm{L}}\right)\right]}
$$

where $E_{\mathrm{p}}$ and $A$ denote the pile elastic modulus and cross-sectional area, respectively, and $w$ is the pile settlement at depth $z$.

For the simple case of homogeneous soil, the Winkler modulus is constant with depth and the head stiffness, $K_{0}$, of a pile of length, $L$, is given by the familiar solution (Mylonakis, 1995; Mylonakis \& Gazetas, 1998; Randolph, 2003; Fleming et al., 2008; Salgado, 2008)

$$
K_{0}=E_{\mathrm{p}} A \lambda \frac{\Omega+\tanh (\lambda L)}{1+\Omega \tanh (\lambda L)}
$$

where $\lambda$ is a load transfer parameter (units of length ${ }^{-1}$ ) and $\Omega$ a dimensionless base stiffness constant

$$
\lambda=\sqrt{\frac{k}{E_{\mathrm{p}} A}}, \Omega=\frac{K_{\mathrm{b}}}{E_{\mathrm{p}} A \lambda}
$$

This paper considers a variable Winkler modulus following the power-law function

$$
k(z)=k_{\mathrm{R}}\left[a+(1-a) \frac{z}{z_{\mathrm{R}}}\right]^{n}, \quad a=\left(\frac{k_{0}}{k_{\mathrm{R}}}\right)^{1 / n}
$$

where $k_{0}$ is the Winkler modulus at the soil surface, $k_{\mathrm{R}}$ the Winkler modulus at a reference depth, $z_{\mathrm{R}}$ and $a$ a

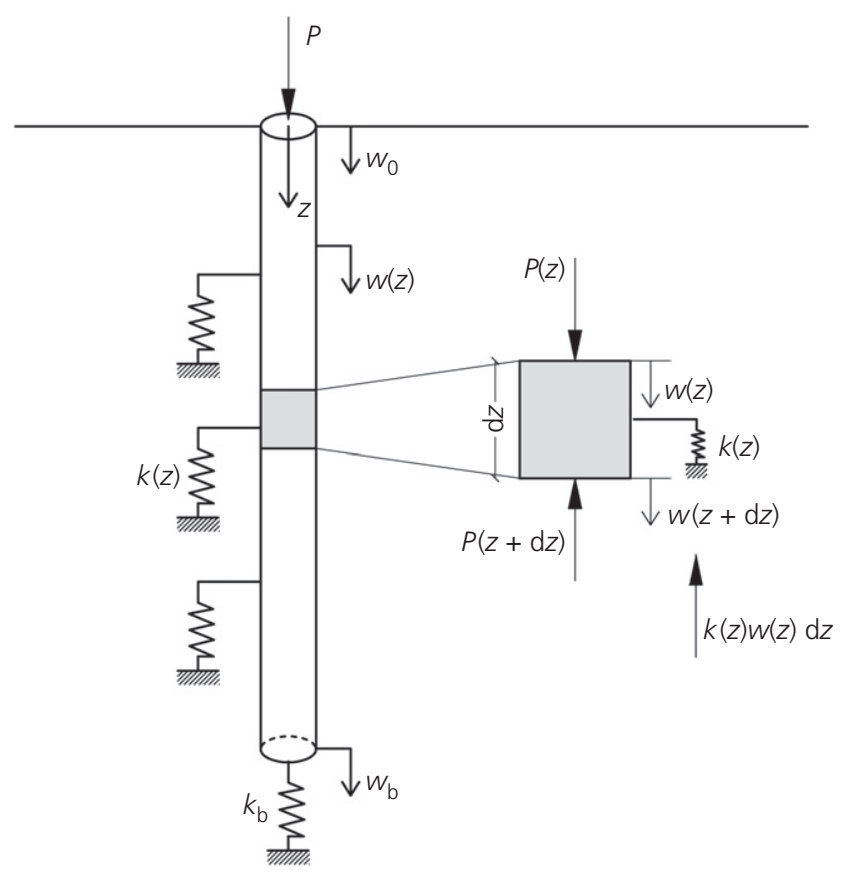

Fig. 1. The Winkler model for a pile under axial load considered where $I_{v}()$ is the modified Bessel functions of the first kind, of order $v$. In the above equations, $\lambda_{\mathrm{R}}, \Omega_{\mathrm{R}}, q, v, \chi_{0}$ and $\chi_{\mathrm{L}}$ denote the parameters

$$
\begin{aligned}
\lambda_{\mathrm{R}} & =\sqrt{\frac{k_{\mathrm{R}}}{E_{\mathrm{p}} A}}, \quad \Omega_{\mathrm{R}}=\frac{K_{\mathrm{b}}}{E_{\mathrm{p}} A \lambda_{\mathrm{R}}}, \\
q & =\left[a+(1-a) \frac{L}{z_{\mathrm{R}}}\right]^{1 / n} \\
v=\frac{1}{n+2}, \quad \chi_{0} & =\frac{2 \lambda_{\mathrm{R}} z_{\mathrm{R}}}{(1-a)(n+2)} a^{(n+2) / 2}, \\
\chi_{\mathrm{L}} & =\frac{2 \lambda_{\mathrm{R}} z_{\mathrm{R}}}{(1-a)(n+2)} q^{(n+2) / 2}
\end{aligned}
$$

The full derivation of this expression is shown in section A1 of the Supplementary Appendix. Alternative forms of equation (5) have been presented by Scott (1981) and Guo (2012).

Equation (5) attains several different special forms which occur at the limits of the parameters $a, n, L$ and $\Omega_{\mathrm{R}}$, which are summarised in Table 1. Additionally, Tables 2 and 3 present solutions for normalised base displacement and base load, respectively, for different base conditions. The derivation of these solutions and alternative representations are provided in sections A2 and A3 of the Supplementary Appendix.

Figure 2 shows normalised plots of pile head stiffness as a function of normalised pile length in which equation (2) is compared with equation (5). Seven Winkler modulus variations are considered by varying $a$ and $n$ and setting the reference depth to the pile length. Each variation is plotted for four dimensionless pile base stiffness values. As expected, when $a=1$ and/or $n=0, k(z)$ is constant with depth and both solutions match. Naturally, the accuracy of equation (2) drops as $k(z)$ deviates from a constant distribution.

Figure 3 shows the percentage error of equation (2) compared with equation (5) as a function of dimensionless pile length for different inhomogeneous soils. If $k_{0} / k_{\mathrm{L}}>0 \cdot 5$ and $\lambda L<2$, which covers a wide range of practical configurations, the discrepancy is less than $10 \%$ which indicates that the homogeneous soil approximation is acceptable. However, for $k_{0} / k_{\mathrm{L}}<0 \cdot 2$, which applies to many normally consolidated soils, this approximation ceases to be acceptable as the error exceeds $30 \%$ beyond $\lambda L=1 \cdot 5$ or so.

\section{NON-LINEAR RESPONSE}

As pile head load increases, the non-linear behaviour of soil gradually dominates response and the above solutions are no longer applicable. Scott (1981) and Guo (2012) propose 
Table 1. Summary of closed-form solutions for pile stiffness in an inhomogeneous soil following a power-law stiffness variation with depth

\begin{tabular}{|c|c|c|c|}
\hline \multirow[t]{2}{*}{$\frac{K_{0}}{E_{\mathrm{p}} A \lambda_{\mathrm{R}}}$} & \multirow[t]{2}{*}{$\begin{array}{l}\text { Homogeneous* } \\
a=1, n=0, \lambda_{\mathrm{R}}=\lambda\end{array}$} & \multicolumn{2}{|c|}{$\begin{array}{l}\text { Inhomogeneous } \dagger \\
\qquad n \neq 0\end{array}$} \\
\hline & & $\begin{array}{l}\text { Vanishing surface stiffness } \\
a=0\end{array}$ & $\begin{array}{l}\text { General case } \\
a \neq 0\end{array}$ \\
\hline $\begin{array}{l}\text { General case } \\
\qquad 0<\lambda_{\mathrm{R}} L<\infty, 0 \leq \Omega_{\mathrm{R}}<\infty\end{array}$ & $\frac{\Omega+\tanh (\lambda L)}{1+\Omega \tanh (\lambda L)}$ & $\left(\lambda_{\mathrm{R}} z_{\mathrm{R}} v\right)^{2 v-1} \frac{\Gamma(1-v)}{\Gamma(v)} \frac{S_{1}}{S_{2}}$ & $a^{n / 2} \frac{q^{n / 2} S_{3}+\Omega_{\mathrm{R}} S_{4}}{q^{n / 2} S_{5}+\Omega_{\mathrm{R}} S_{6}}$ \\
\hline Perfectly floating pile, $\Omega_{\mathrm{R}}=0$ & $\tanh (\lambda L)$ & $\left(\lambda_{\mathrm{R}} z_{\mathrm{R}} v\right)^{2 v-1} \frac{\Gamma(1-v)}{\Gamma(v)} \frac{I_{1-v}\left(\chi_{\mathrm{L}}\right)}{I_{v-1}\left(\chi_{\mathrm{L}}\right)}$ & $a^{n / 2} \frac{S_{3}}{S_{5}}$ \\
\hline Perfectly end-bearing pile, $\Omega_{R} \rightarrow \infty$ & $\frac{1}{\tanh (\lambda L)}$ & $\left(\lambda_{\mathrm{R}} z_{\mathrm{R}} v\right)^{2 v-1} \frac{\Gamma(1-v)}{\Gamma(v)} \frac{I_{-v}\left(\chi_{\mathrm{L}}\right)}{I_{+v}\left(\chi_{\mathrm{L}}\right)}$ & $a^{n / 2} \frac{S_{4}}{S_{6}}$ \\
\hline Infinitely long pile, $\lambda_{\mathrm{R}} L \rightarrow \infty$ & 1 & $\left(\lambda_{\mathrm{R}} z_{\mathrm{R}} v\right)^{2 v-1} \frac{\Gamma(1-v)}{\Gamma(v)}$ & $a^{n / 2} \frac{I_{v-1}\left(\chi_{0}\right)-I_{1-v}\left(\chi_{0}\right)}{I_{-v}\left(\chi_{0}\right)-I_{+v}\left(\chi_{0}\right)}$ \\
\hline Zero length pile, $\lambda_{\mathrm{R}} L=0$ & $\Omega$ & $\Omega_{\mathrm{R}}$ & $\Omega_{\mathrm{R}}$ \\
\hline
\end{tabular}

*After Mylonakis (1995) and Mylonakis \& Gazetas (1998).

$\dagger$ For $n=0$ these solutions reproduce those for homogeneous soil (in the first column).

Dimensionless parameters $\lambda_{\mathrm{R}}, \Omega_{\mathrm{R}}, a, q, v, \chi_{0}$ and $\chi_{\mathrm{L}}$ are provided in equations (4) and (6), $\Gamma()=$ gamma function, $S_{1}=q^{n / 2} I_{1-v}\left(\chi_{\mathrm{L}}\right)+\Omega_{\mathrm{R}} I_{-v}\left(\chi_{\mathrm{L}}\right)$, $S_{2}=q^{n / 2} I_{v-1}\left(\chi_{\mathrm{L}}\right)+\Omega_{\mathrm{R}} I_{+v}\left(\chi_{\mathrm{L}}\right), S_{3}=I_{v-1}\left(\chi_{0}\right) I_{1-v}\left(\chi_{\mathrm{L}}\right)-I_{1-v}\left(\chi_{0}\right) I_{v-1}\left(\chi_{\mathrm{L}}\right), S_{4}=I_{v-1}\left(\chi_{0}\right) I_{-v}\left(\chi_{\mathrm{L}}\right)-I_{1-v}\left(\chi_{0}\right) I_{+v}\left(\chi_{\mathrm{L}}\right), S_{5}=I_{-v}\left(\chi_{0}\right) I_{v-1}\left(\chi_{\mathrm{L}}\right)-I_{+v}\left(\chi_{0}\right) I_{1-v}\left(\chi_{\mathrm{L}}\right)$, $S_{6}=I_{-v}\left(\chi_{0}\right) I_{+v}\left(\chi_{\mathrm{L}}\right)-I_{+v}\left(\chi_{0}\right) I_{-v}\left(\chi_{\mathrm{L}}\right)$

Table 2. Summary of closed-form solutions for normalised pile base displacement in an inhomogeneous soil following a power-law stiffness variation with depth

\begin{tabular}{l|l|l|l}
\hline$\frac{w_{\mathrm{b}}}{w}$ & $\begin{array}{l}\text { Homogeneous } \\
a=1, n=0, \lambda_{\mathrm{R}}=\lambda\end{array}$ & \multicolumn{2}{|c}{$\begin{array}{c}\text { Inhomogeneous* } \\
n \neq 0\end{array}$} \\
\cline { 2 - 4 } & $\begin{array}{l}\text { Vanishing surface stiffness } \\
a=0\end{array}$ & $\begin{array}{l}\text { General case } \\
a \neq 0\end{array}$ \\
$\begin{array}{l}\text { General case } \\
0<\lambda_{\mathrm{R}} L<\infty, 0 \leq \Omega_{\mathrm{R}}<\infty\end{array}$ & $\frac{1}{\Omega \sinh (\lambda L)+\cosh (\lambda L)}$ & $\frac{\left(\lambda_{\mathrm{R}} z_{\mathrm{R}} v\right)^{v-1}}{q^{1 / 2} \Gamma(v) S_{2}}$ & $\frac{2 q^{(n+1) / 2} \sin (\pi v)}{\pi a^{1 / 2} \chi_{\mathrm{L}}\left[q^{n / 2} S_{5}+\Omega_{\mathrm{R}} S_{6}\right]}$ \\
$\begin{array}{l}\text { Perfectly floating pile, } \Omega_{\mathrm{R}}=0 \\
\text { Perfectly end-bearing pile, } \Omega_{\mathrm{R}} \rightarrow \infty\end{array}$ & $\frac{1}{\cosh (\lambda L)}$ & $\frac{\left(\lambda_{\mathrm{R}} z_{\mathrm{R}} v\right)^{v-1}}{q^{(n+1) / 2} \Gamma(v) I_{v-1}\left(\chi_{\mathrm{L}}\right)}$ & $\frac{2 q^{1 / 2} \sin (\pi v)}{\pi a^{1 / 2} \chi_{\mathrm{L}} S_{5}}$ \\
\hline
\end{tabular}

*For $n=0$ these solutions reproduce those for homogeneous soil (in the first column).

Dimensionless parameters $\lambda_{\mathrm{R}}, \Omega_{\mathrm{R}}, a, q, v, \chi_{0}$ and $\chi_{\mathrm{L}}$ are provided in equations (4) and $(6), \Gamma()=$ gamma function, $S_{2}=q^{n / 2} I_{v-1}\left(\chi_{\mathrm{L}}\right)+\Omega_{\mathrm{R}} I_{+v}\left(\chi_{\mathrm{L}}\right)$, $S_{5}=I_{-v}\left(\chi_{0}\right) I_{v-1}\left(\chi_{\mathrm{L}}\right)-I_{+v}\left(\chi_{0}\right) I_{1-v}\left(\chi_{\mathrm{L}}\right), S_{6}=I_{-v}\left(\chi_{0}\right) I_{+v}\left(\chi_{\mathrm{L}}\right)-I_{+v}\left(\chi_{0}\right) I_{-v}\left(\chi_{\mathrm{L}}\right)$

Table 3. Summary of closed-form solutions for normalised pile base load in an inhomogeneous soil following a power-law stiffness variation with depth

\begin{tabular}{l|l|l|l}
\hline $\begin{array}{l}P_{\mathrm{b}} \\
P\end{array}$ & $\begin{array}{l}\text { Homogeneous } \\
a=1, n=0, \lambda_{\mathrm{R}}=\lambda\end{array}$ & \multicolumn{2}{|c}{$\begin{array}{c}\text { Inhomogeneous* } \\
n \neq 0\end{array}$} \\
\cline { 2 - 4 } & & $\begin{array}{l}\text { General case } \\
a \neq 0\end{array}$ \\
$\begin{array}{l}\text { General case } \\
0<\lambda_{\mathrm{R}} L<\infty, 0 \leq \Omega_{\mathrm{R}}<\infty\end{array}$ & $\frac{\Omega}{\Omega \cosh (\lambda L)+\sinh (\lambda L)}$ & $\frac{\Omega_{\mathrm{R}}\left(\lambda_{\mathrm{R}} z_{\mathrm{R}} v\right)^{-v}}{q^{1 / 2} \Gamma(1-v) S_{1}}$ & $\frac{2 q^{(n+1) / 2} \Omega_{\mathrm{R}} \sin (\pi v)}{\pi a^{(n+1) / 2} \chi_{\mathrm{L}}\left[q^{n / 2} S_{3}+\Omega_{\mathrm{R}} S_{4}\right]}$ \\
$\begin{array}{l}\text { Perfectly floating pile, } \Omega_{\mathrm{R}}=0 \\
\text { Perfectly end-bearing pile, } \Omega_{\mathrm{R}} \rightarrow \infty\end{array}$ & 0 & 0 & 0 \\
\hline
\end{tabular}

*For $n=0$ these solutions reproduce those for homogeneous soil (in the first column).

Dimensionless parameters $\lambda_{\mathrm{R}}, \Omega_{\mathrm{R}}, a, q, v, \chi_{0}$ and $\chi_{\mathrm{L}}$ are provided in equations (4) and (6), $\Gamma()=$ gamma function, $S_{1}=q^{n / 2} I_{1-v}\left(\chi_{\mathrm{L}}\right)+\Omega_{\mathrm{R}} I_{-v}\left(\chi_{\mathrm{L}}\right)$, $S_{3}=I_{v-1}\left(\chi_{0}\right) I_{1-v}\left(\chi_{\mathrm{L}}\right)-I_{1-v}\left(\chi_{0}\right) I_{v-1}\left(\chi_{\mathrm{L}}\right), S_{4}=I_{v-1}\left(\chi_{0}\right) I_{-v}\left(\chi_{\mathrm{L}}\right)-I_{1-v}\left(\chi_{0}\right) I_{+v}\left(\chi_{\mathrm{L}}\right)$ 


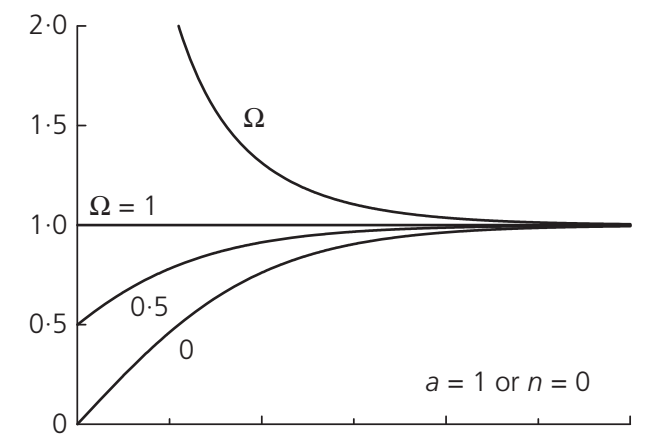

- Exact winkler solution, equation (5)

--- Approximate solution, equation (2)

$$
\begin{aligned}
& k(z)=k_{\mathrm{L}}\left[a+(1-a) \frac{z}{L}\right]^{\mathrm{n}} \\
& \lambda=\lambda_{\mathrm{R}} \sqrt{\frac{k_{\mathrm{av}}}{k_{\mathrm{L}}}} \\
& \Omega=\Omega_{\mathrm{R}} \sqrt{\frac{k_{\mathrm{L}}}{k_{\mathrm{av}}}}
\end{aligned}
$$
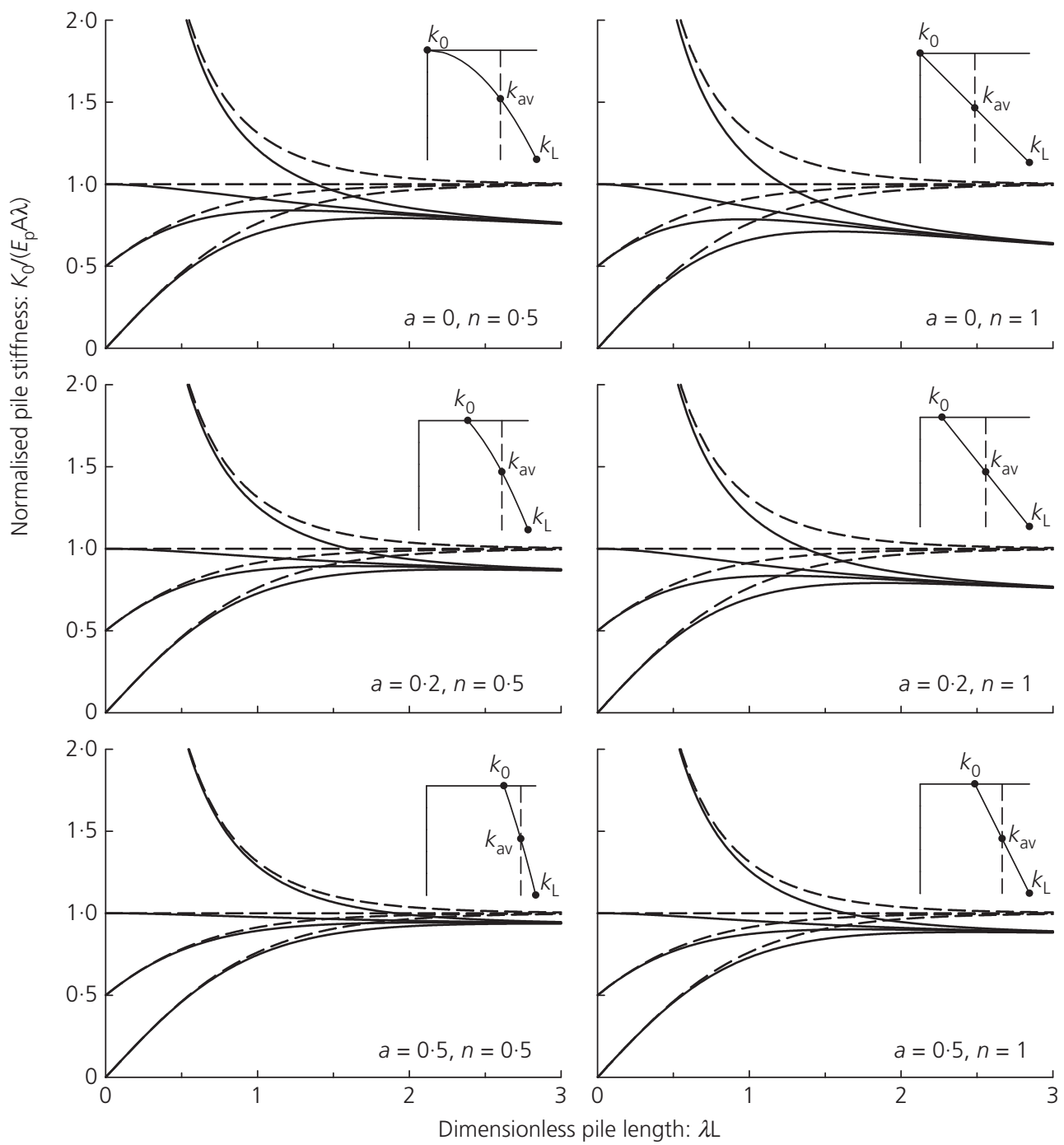

Fig. 2. Variation of elastic pile head stiffness with length for different degrees of inhomogeneity

a simple family of models to describe the non-linear shaft and base resistance of the pile, shown in Fig. 4. In this approach, linear elastic Winkler springs are replaced by linear elastic-perfectly plastic ' $t-z$ ' curves, with elastic stiffness equal to $k(z)$ and ultimate skin friction per unit pile length, $t_{\mathrm{u}}(z)$, that can be established using traditional means (e.g. the $\alpha$-method, Skempton, 1959 or the $\beta$-method, Burland, 1973). To derive a simple solution, the additional assumption is made that yielding originates at the pile top and propagates downwards. A sufficient condition to this end is that the displacement at yield at depth $z$, $w_{\mathrm{y}}(z)=t_{\mathrm{u}}(z) / k(z)$, must be a non-strictly increasing function of depth. Finally, the base spring is assumed to behave linearly until the whole shaft friction is mobilised, transitioning to perfectly plastic behaviour beyond a base settlement, $w_{\text {by }}$ The corresponding ultimate load can then be calculated using traditional bearing capacity approaches (e.g. Skempton, 1959; Salgado, 2008; Viggiani et al., 2011).

Figure 4 shows the general case where the head load, $P$, is such that the shaft resistance has reached its limiting value, $t_{\mathrm{u}}(z)$, over a certain length, $L_{\mathrm{p}}$. To calculate the corresponding settlement for a given applied load, $L_{\mathrm{p}}$ must be determined, but this is not trivial as the associated equations are transcendental. Instead, $L_{\mathrm{p}}$ can be taken as a known parameter and the rest of the solution, including forces and displacements, calculated as a function of $L_{\mathrm{p}}$. Repeating this for a series of $L_{\mathrm{p}}$ values provides a complete load-settlement curve. 


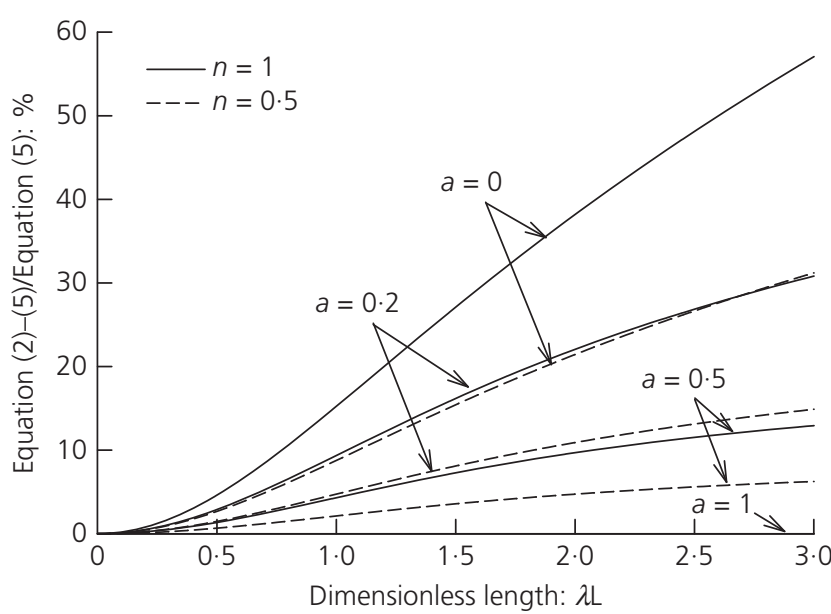

Fig. 3. Percentage error in elastic pile head stiffness calculated using equation (2) and the exact Winkler solution in equation (5). As equation (2) overestimates stiffness, the values in the graph are always positive

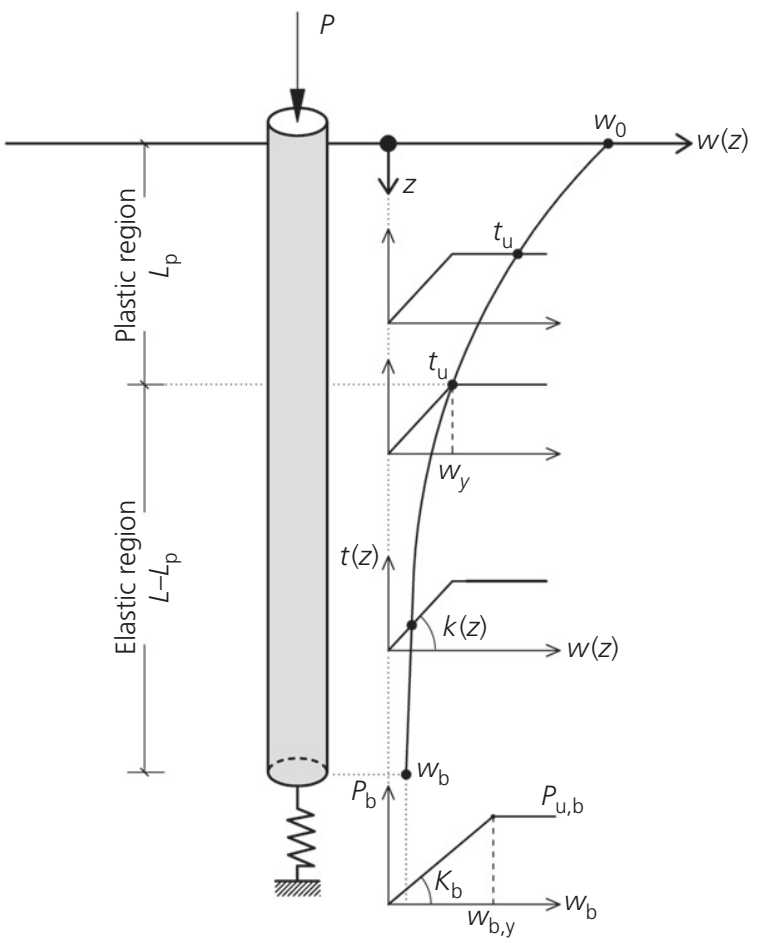

Fig. 4. Non-linear pile settlement model considered

In the realm of the above approach, the load-settlement response of the pile can be split into four stages, shown in Fig. 5

(a) Linear elastic response, $L_{\mathrm{p}}=0$. Before the yield displacement at the top of the pile, $w_{\mathrm{y}}(0)$, is reached, equation (5) can be used directly.

(b) Non-linear shaft behaviour, $0<L_{\mathrm{p}}<L$. For an assumed plastic length, $L_{\mathrm{p}}$, the pile axial force at the plastic-elastic interface can be calculated by multiplying the yield displacement at that depth, $w_{\mathrm{y}}\left(L_{\mathrm{p}}\right)$, by the stiffness of the elastic pile section below, $K_{\mathrm{el}}$, from equation (5) with $L_{\mathrm{p}}-L$ as the pile length. The plastic section can then be treated as a rod under known base and distributed shaft loads to obtain both the load and settlement at the pile head.

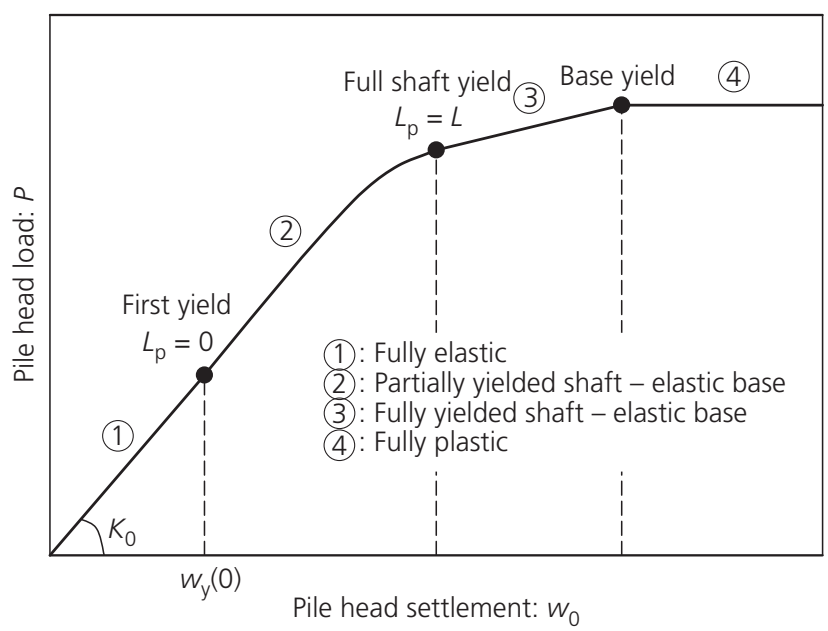

Fig. 5. Pile head load-settlement curve in the realm of the proposed analysis

(c) Shaft resistance exhausted, $L_{\mathrm{p}}=L$. The behaviour of the pile is now governed by base response. A pile base settlement, $w_{\mathrm{b}}$, can be input into the load-settlement curve of the base to get a reaction. The shaft can then be treated as a rod with known distributed load.

(d) Base resistance exhausted, $w_{\mathrm{b}}=w_{\mathrm{by}}$. There is no additional resistance to load, therefore the applied head load, $P$, is equal to the ultimate resistance, $P_{\mathrm{u}}$, and head displacement increases without limit.

Considering a power-law variation in ultimate shaft resistance per unit length, $t_{\mathrm{u}}(z)$, with exponent, $m$, and surface value $t_{\mathrm{u}, 0}$; the load, $P$, and displacement, $w_{0}$, at the pile head are given by the following parametric expressions

$$
\begin{aligned}
P= & P\left(L_{\mathrm{p}}\right)+t_{\mathrm{u} 0} L_{\mathrm{p}}+\frac{t_{\mathrm{u}}\left(L_{\mathrm{p}}\right)-t_{\mathrm{u} 0}}{m+1} L_{\mathrm{p}} \\
w_{0}= & w\left(L_{\mathrm{p}}\right)+\frac{P\left(L_{\mathrm{p}}\right)}{E_{\mathrm{p}} A} L_{\mathrm{p}}+\frac{t_{\mathrm{u} 0}}{2 E_{\mathrm{p}} A} L_{\mathrm{p}}^{2} \\
& +\frac{t_{\mathrm{u}}\left(L_{\mathrm{p}}\right)-t_{\mathrm{u} 0}}{(m+2) E_{\mathrm{p}} A} L_{\mathrm{p}}^{2}
\end{aligned}
$$

where $w\left(L_{\mathrm{p}}\right), P\left(L_{\mathrm{p}}\right)$ and $t_{\mathrm{u}}\left(L_{\mathrm{p}}\right)$ are the axial displacement, load and ultimate shaft resistance per unit length at the interface depth, $z=L_{\mathrm{p}}$, respectively. $w\left(L_{\mathrm{p}}\right)$ and $P\left(L_{\mathrm{p}}\right)$ depend on the response stage being considered, for stage 2, $w\left(L_{\mathrm{p}}\right)=w_{\mathrm{y}}\left(L_{\mathrm{p}}\right)$ and $P\left(L_{\mathrm{p}}\right)=w_{\mathrm{y}}\left(L_{\mathrm{p}}\right) K_{\mathrm{el}}$, where $K_{\mathrm{el}}$ is the head stiffness of the elastic region of the pile, obtained from equation (5). For stages 3 and 4, the shaft resistance is exhausted, therefore, the interface depth is at the pile base, $L_{\mathrm{p}}=L$, and the load and displacement at this depth are given by the base load-settlement curve, $w\left(L_{\mathrm{p}}\right)=w_{\mathrm{b}}$ and $P\left(L_{\mathrm{p}}\right)=P_{\mathrm{b}}$. Note that as the base spring is modelled as linear elastic, the pile head load, $P$, varies linearly with pile head settlement, $w_{0}$, in stage 3 .

The derivation of these expressions is shown in section A4 of the Supplementary Appendix. Guo (2012) presents alternative forms of equations (7) and (8).

The above solution provides a closed-form alternative to the popular method by Coyle \& Reese (1966), which, unlike the proposed one, is iterative. Additionally, the proposed solution does not require discretising the pile into elements, the number of which can affect the accuracy of the calculation in the iterative method. In fact, choosing different $L_{\mathrm{p}}$ values only increases the number of points 
used to plot the full load-settlement curve with each point being an exact result. However, discretising the pile into a sufficient number of elements and/or performing enough iterations will yield identical results to this solution at any required precision. It is therefore up to the designer/modeller to select their preferred method.

\section{APPLICATION TO PILE LOAD TESTS IN LONDON CLAY} Whitaker \& Cooke (1966) conducted 11 maintained load tests on straight-shafted and under-reamed piles embedded in London Clay in the Wembley area. The pile dimensions are summarised in Table 4. The method described in this paper is applied here to predict the load-settlement response of these piles. To this end

(a) Ultimate skin friction, $t_{\mathrm{u}}(z)$, is estimated using the $\alpha$-method (Skempton, 1959; Patel, 1992): $t_{\mathrm{u}}(z)=\alpha c_{\mathrm{u}}(z)$ $\pi D_{\mathrm{s}}$ where $D_{\mathrm{s}}$ is the shaft diameter, $c_{\mathrm{u}}(z)$ the undrained shear strength, derived from triaxial tests on $38 \mathrm{~mm}$ samples by Whitaker \& Cooke (1966) and reduced by a factor of 1.3 to account for the underestimation of fissured strength by tests on $38 \mathrm{~mm}$ samples (Patel, 1992) and $\alpha$ the pile-soil adhesion factor, taken here as 0.5 for London Clay (Patel, 1992; LDSA, 2017).

(b) The ultimate load at the pile base, $P_{\mathrm{ub}}$, is obtained using Skempton (1951): $P_{\mathrm{ub}}=N_{\mathrm{c}} c_{\mathrm{u}}(L) \pi D_{\mathrm{b}}^{2} / 4$, where $N_{\mathrm{c}}$ is the bearing capacity factor, taken here as 9 and $D_{\mathrm{b}}$ the base diameter.

(c) The Winkler modulus, $k(z)$, is related to soil shear modulus, $G_{\mathrm{s}}=G_{\mathrm{s}}(z)$, using the concentric cylinder theory of Cooke (1974) and Randolph \& Wroth (1978): $k(z) \simeq 2 \pi G_{\mathrm{s}}(z) / \ln \left(2 r_{\mathrm{m}} / D_{\mathrm{s}}\right)$, where $v_{\mathrm{s}}$ is the soil Poisson's ratio and $r_{\mathrm{m}}$ an empirical radius beyond which displacement due to the load on the pile is presumed to reach zero. $r_{\mathrm{m}}$ was estimated by Randolph \& Wroth (1978) by matching Winkler analyses to numerical solutions of the full continuum problem, to get: $r_{\mathrm{m}} \approx 2 \cdot 5 L\left(1-v_{\mathrm{s}}\right) G_{\mathrm{s}}(L / 2) / G_{\mathrm{s}}(L)$. Guo (2012) developed enhanced formulations for $r_{\mathrm{m}}$ and identified some dependence on soil inhomogeneity. Mylonakis \& Gazetas (1998) showed that the resulting Winkler modulus is rather insensitive to $r_{\mathrm{m}}$ for piles of practical dimensions so the above expression is used here.

(d) The stiffness of the pile base spring, $K_{\mathrm{b}}$, is approximated as a rigid punch on a half-space (Randolph \& Wroth, 1978): $K_{\mathrm{b}} \simeq 2 G_{\mathrm{s}}(L) D_{\mathrm{b}} /\left(1-v_{\mathrm{s}}\right) \eta$, where $\eta=$ a factor to account for depth below the ground surface, taken as unity.

(e) A relationship between maximum shear modulus, $G_{0}$, and $c_{\mathrm{u}}$ is obtained from Vardanega \& Bolton (2011a), who analysed high-quality triaxial tests in London Clay and derived the correlation: $G_{0} \approx 320 c_{\mathrm{u}}$, which is in meaningful agreement with the recommendations by Poulos (1989).

( $f$ ) For shaft resistance and the early stages of base resistance, $G_{0}$ will adequately predict settlements, therefore it is used to derive the Winkler modulus and pile base stiffness for stages 1 and 2 . However, as more base resistance is mobilised, $G_{0}$ will under-predict settlements, therefore a different model is required for stage 3 of the response. Vardanega \& Bolton (2011b) proposed a simple power-law equation to describe soil shear stress-strain $(\tau-\gamma)$ response

$$
\frac{\tau(\gamma)}{c_{\mathrm{u}}}=\frac{1}{2}\left(\frac{\gamma}{\gamma_{50}}\right)^{b}
$$

where $\gamma_{50}$ is the shear strain at $50 \%$ of the undrained shear strength and $b$ is an exponent. Vardanega \& Bolton (2011a) found that the tests on London Clay had an average $b$ value of 0.58 and a $\gamma_{50}$ of about $7 \times 10^{-3}$. A secant shear modulus between the estimated mobilisation shear strength of the base at the beginning of stage 3 and at failure interpreted from this model is used to predict the pile base stiffness for stage 3. The elastic portion of the base spring is, therefore, modelled as bilinear.

Predicted and measured load-settlement curves for the straight-shafted piles are shown in Fig. 6 and for the under-reamed piles in Fig. 7. The good agreement for small settlements indicates that the adopted shear modulus variation is realistic. Although the linear elastic-perfectly plastic model provides a sharper transition to yielding, the non-linear response is also approximated satisfactorily. In particular, the bilinear model for the pile base satisfactorily reproduces the response after shaft resistance is exhausted.

\section{CONCLUSIONS}

A simple analytical solution was derived for the analysis of elastic and inelastic settlement of an axially loaded pile in inhomogeneous soil obeying a power-law variation in stiffness and strength with depth. The solution makes use of the Winkler assumption and models soil-pile interaction using elastic and elastic-perfectly plastic springs distributed along the pile, and a concentrated spring at the pile base. The main findings of the study are as follows.

(a) An exact elastic Winkler solution was derived for pile stiffness (equation 5), in a simpler form than the earlier solutions by Scott (1981) and Guo (2012). In addition,

Table 4. Dimensions of the piles tested by Whitaker \& Cooke (1966) in Figs 6 and 7

\begin{tabular}{|c|c|c|c|c|c|c|}
\hline Type & Pile & $L: \mathrm{m}$ & $D_{\mathrm{s}}: \mathrm{m}$ & $D_{\mathrm{b}}: \mathrm{m}$ & $L / D_{\mathrm{s}}$ & $D_{\mathrm{b}} / D_{\mathrm{s}}$ \\
\hline \multirow[t]{5}{*}{ Straight-shafted } & G & $9 \cdot 4$ & 0.77 & 0.77 & $12 \cdot 1$ & $1 \cdot 0$ \\
\hline & D & $9 \cdot 3$ & 0.64 & 0.64 & $14 \cdot 6$ & $1 \cdot 0$ \\
\hline & $\mathrm{H}$ & $12 \cdot 2$ & 0.77 & 0.77 & $15 \cdot 8$ & $1 \cdot 0$ \\
\hline & $\mathrm{N}$ & $15 \cdot 2$ & 0.94 & 0.94 & $16 \cdot 2$ & $1 \cdot 0$ \\
\hline & $\mathrm{K}$ & $15 \cdot 2$ & 0.80 & 0.80 & $19 \cdot 0$ & $1 \cdot 0$ \\
\hline \multirow[t]{6}{*}{ Under-reamed } & $\mathrm{L}$ & $8 \cdot 2$ & 0.77 & $1 \cdot 68$ & $12 \cdot 3$ & $2 \cdot 2$ \\
\hline & $\mathrm{E}$ & $8 \cdot 1$ & 0.63 & $1 \cdot 22$ & $14 \cdot 7$ & 1.9 \\
\hline & A & $11 \cdot 0$ & $0 \cdot 79$ & $1 \cdot 68$ & $15 \cdot 5$ & $2 \cdot 1$ \\
\hline & $\mathrm{P}$ & $14 \cdot 5$ & $0 \cdot 94$ & $1 \cdot 85$ & $17 \cdot 3$ & $2 \cdot 0$ \\
\hline & $\mathrm{F}$ & $11 \cdot 1$ & $0 \cdot 62$ & $1 \cdot 22$ & $19 \cdot 5$ & $2 \cdot 0$ \\
\hline & M & $14 \cdot 6$ & 0.77 & 1.68 & $20 \cdot 7$ & $2 \cdot 2$ \\
\hline
\end{tabular}




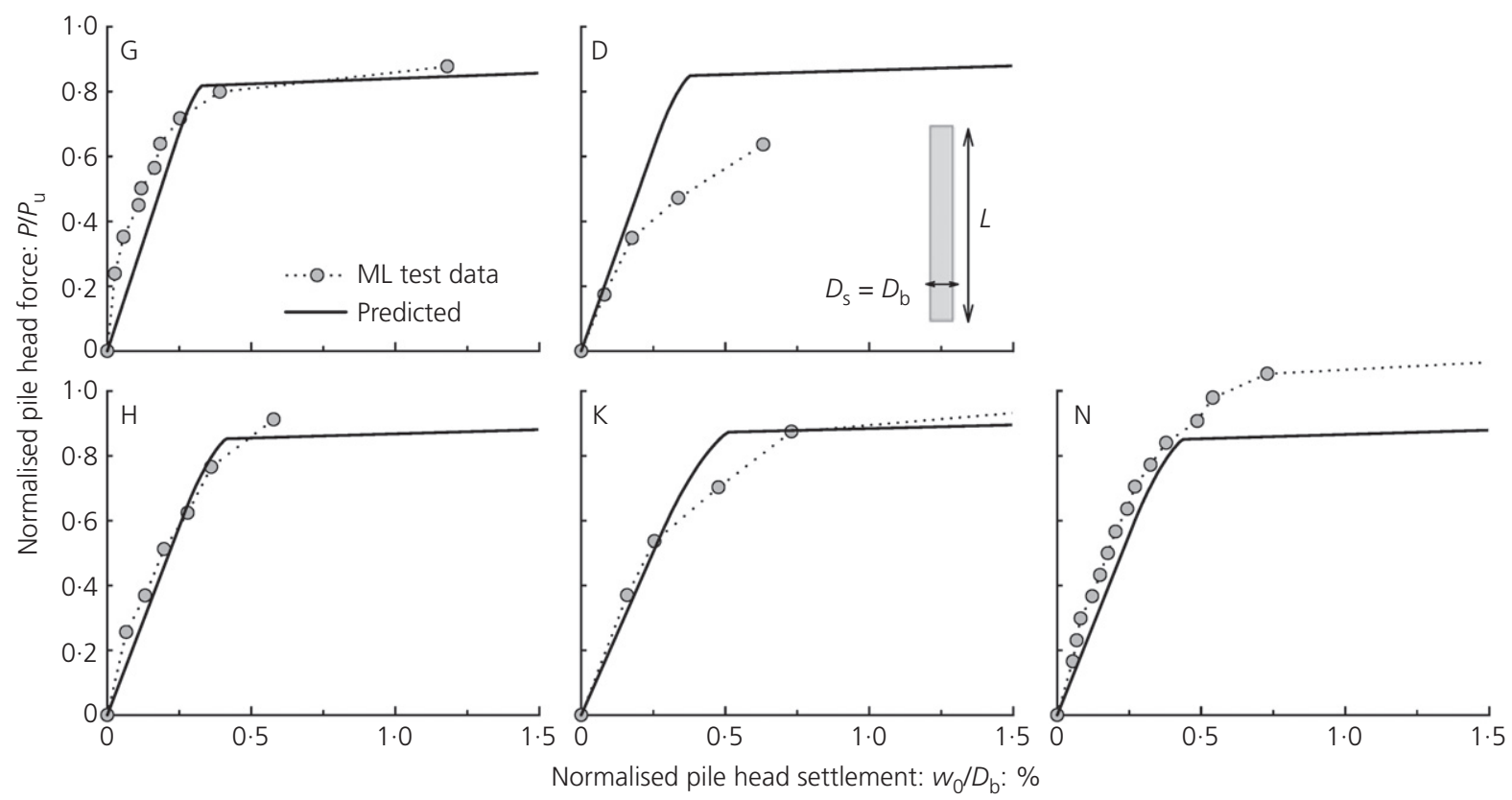

Fig. 6. Comparison of the predictions of the current model against the experimental measurements on straight-shafted piles by Whitaker \& Cooke (1966)
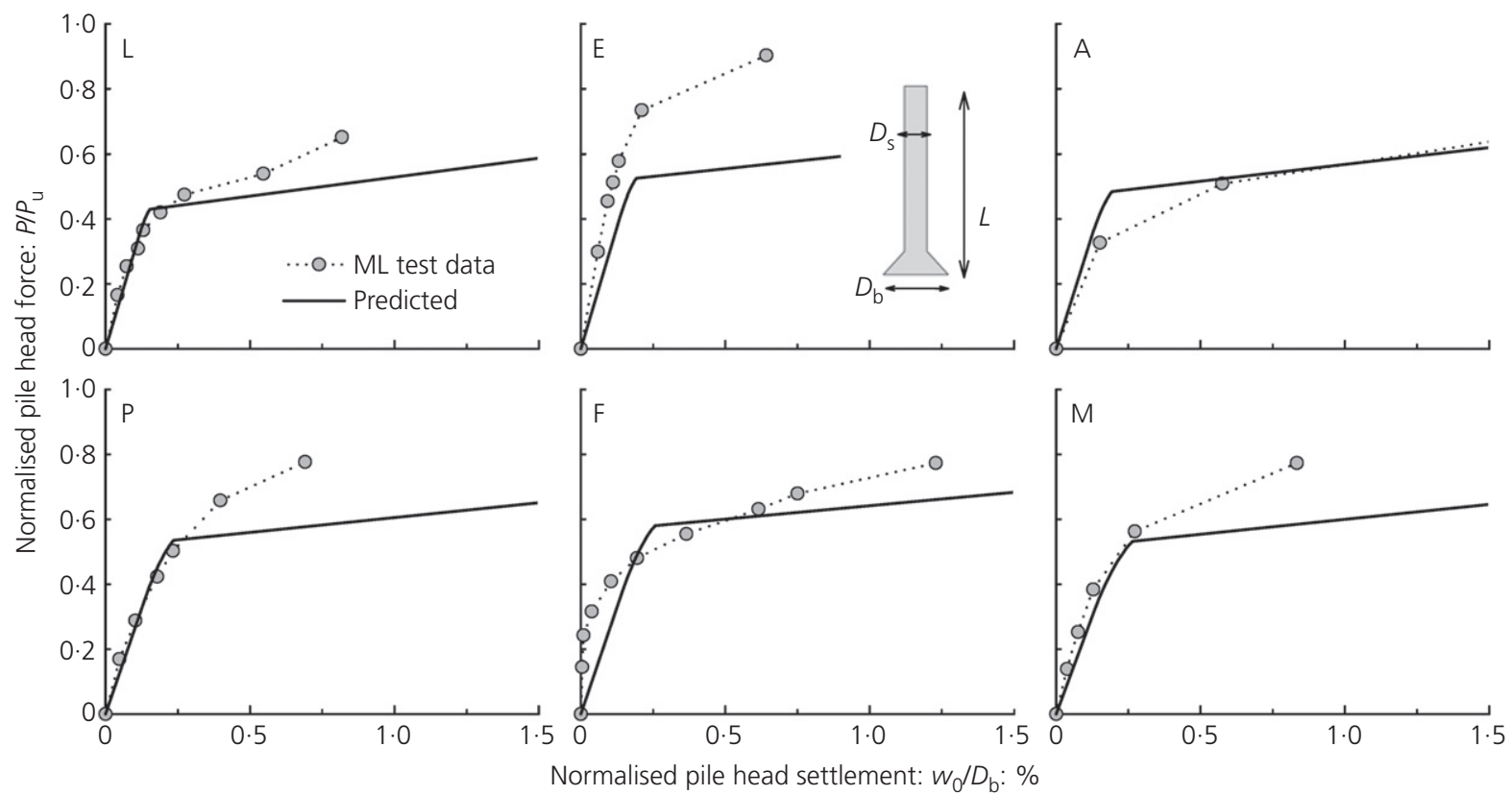

Fig. 7. Comparison of the predictions of the current model against the experimental measurements on under-reamed piles by Whitaker \& Cooke (1966)

some limiting cases, including those for zero surface stiffness, perfectly end-bearing, perfectly floating, infinitely long and short piles, were derived for the first time (Table 1).

(b) A parametric investigation of the general solution indicates that for $k_{0} / k_{\mathrm{L}}$ less than $0 \cdot 5$, employing an equivalent homogeneous soil profile with average properties does not work for pile lengths $\lambda L$ greater than 1.5 (error $>20 \%$ ), thus inhomogeneity should be explicitly modelled. To this end, Fig. 2 is suitable as a design chart. Further investigation into the accuracy of other approximate solutions can be found in Crispin et al. (2018). (c) Under the assumption of soil yielding propagating downwards, the solution was extended to the inelastic regime considering elastic-perfectly plastic ' $t-z$ ' and base springs, expressed as a function of depth of the yield zone, $L_{\mathrm{p}}$.

(d) Using common site investigation data, such as $c_{\mathrm{u}}(z)$, a database of high-quality tests in London Clay, and simple formulations to relate these properties to model parameters such as $k(z)$, a successful comparison was presented against the classical measurements by Whitaker \& Cooke (1966). The application of this method to a database of pile tests in London Clay can be found in Voyagaki et al. (2018). 
As a final remark, the solution presented here can be applied to more general classes of elastic and elastoplastic Winkler beds (e.g. exponentially varying stiffness with depth, hyperbolic ' $t-z$ ' and base resistance curves). It can also be extended to calculate interaction factors between piles in a group using the three-step method proposed in Mylonakis \& Gazetas (1998). However, this lies beyond the scope of this study.

\section{ACKNOWLEDGEMENTS}

The authors thank Dr. Paul Vardanega and Dr. Elia Voyagaki for their valuable support in the preparation of this paper. The first author is supported by the Engineering and Physical Sciences Research Council (grant number EP/N509619/1). No new experimental data were collected during this study.

\section{REFERENCES}

Anoyatis G. (2013). Contribution to kinematic and inertial analysis of piles by analytical and experimental methods. $\mathrm{PhD}$ thesis, University of Patras, Patras, Greece.

Anoyatis G., Mylonakis G. \& Tsikas A. (2018). An analytical continuum model for Winkler modulus of axially-loaded end-bearing piles in inhomogeneous soil. Int. J. Numer. Anal. Methods Geomech., http://dx.doi.org/10.1002/nag.2886.

Burland J. B. (1973). Shaft friction of piles in clay - a simple fundamental approach. Ground Engng 7, No. 4, 30-42.

Cooke R. W. (1974). The settlement of friction pile foundations. Proceedings of the conference on tall building, Kuala Lumpur, Malaysia, pp. 7-19.

Coyle H. M. \& Reese L. C. (1966). Load transfer for axially loaded piles in clay. J. Soil Mech. Found. Div. ASCE 92, No. 2, 1-26.

Crispin J. J., Su H., Round K. \& Mylonakis G. (2018). Energy formulation for axial pile head stiffness in inhomogeneous soil. In Sustainability issues for the deep foundations (eds H. El-Naggar, K. Abdel-Rahman, B. Fellenius and H. Shehata), pp. 181-190. Cham, Switzerland: Springer.

Fleming K., Weltman A., Randolph M. \& Elson K. (2008). Piling engineering, 3rd edn. Abdingdon, UK: Taylor \& Francis.

Guo W. D. (2012). Theory and practice of pile foundations, $1 \mathrm{st}$ edn. Boca Raton, FL, USA: CRC Press.

LDSA (London District Surveyors Association) (ed.) (2017). Guidance notes for the design of straight shafted bored piles in London Clay. Bromley, UK: LDSA Publications.

Mylonakis G. (1995). Contributions to static and seismic analysis of piles and pile-supported bridge piers. $\mathrm{PhD}$ thesis, State University of New York at Buffalo, New York, NY, USA.
Mylonakis G. (2001a). Winkler modulus for axially loaded piles. Géotechnique 51, No. 5, 455-461.

Mylonakis G. (2001b). Elastodynamic model for large-diameter end-bearing shafts. Soils Found. 41, No. 3, 31-44.

Mylonakis G. \& Gazetas G. (1998). Settlement and additional internal forces of grouped piles in layered soil. Géotechnique 48, No. 1, 55-72.

Patel D. (1992). Interpretation of pile tests in London Clay. In Piling: European practice and worldwide trends (ed. M. J. Sands), pp. 100-110. London, UK: Thomas Telford.

Poulos H. G. (1989). Pile behaviour - theory and application. Géotechnique 39, No. 3, 365-415.

Poulos H. G. \& Davis E. H. (1980). Pile foundation analysis and design. New York, NY, USA: Wiley.

Randolph M. F. (2003). Science and empiricism in pile foundation design. Géotechnique 53, No. 10, 847-875.

Randolph M. F. \& Wroth C. P. (1978). Analysis of deformation of vertically loaded piles. J. Geotech. Engng ASCE 104, No. 12, $1465-1488$.

Salgado R. (2008). The engineering of foundations, International edition. New York, NY, USA: McGraw-Hill.

Scott R. F. (1981). Foundation analysis, 1st edn. Englewood Cliffs, NJ, USA: Prentice-Hall.

Skempton A. W. (1951). The bearing capacity of clay. In Proceedings of the buildings research congress, London, vol. 1, pp. 180-189.

Skempton A. W. (1959). Cast in-situ bored piles in London Clay. Géotechnique 9, No. 4, 153-173.

Syngros K. (2004). Seismic response of piles and pile-supported bridge piers evaluated through case histories. $\mathrm{PhD}$ thesis, The City College of the City University of New York, New York, NY, USA.

Vardanega P. J. \& Bolton M. D. (2011a). Predicting shear strength mobilisation of London Clay. In Proceedings of the 15th European conference on soil mechanics and geotechnical engineering: geotechnics of hard soils - weak rocks (eds A. Anagnostopoulos, M. Pachakis and C. Tsatsanifos), vol. 1, pp. 487-492. Amsterdam, the Netherlands: IOS Press BV.

Vardanega P. J. \& Bolton M. D. (2011b). Strength mobilization in clays and silts. Can. Geotech. J. 48, No. 10, 1485-1503.

Viggiani C., Mandolini A. \& Russo G. (2011). Piles and pile foundations. Boca Raton, FL, USA: CRC Press.

Voyagaki E., Crispin J. J., Gilder C. E. L., Nowak P., O'Riordan N., Patel D. \& Vardanega P. J. (2018). Analytical approaches to predict pile settlement in London Clay. In Sustainability issues for the deep foundations (eds H. El-Naggar, K. AbdelRahman, B. Fellenius and H. Shehata), pp. 162-180. Cham, Switzerland: Springer.

Whitaker T. \& Cooke R. W. (1966). An investigation of the shaft and base resistance of large bored piles in London Clay. In Large bored piles, proceedings of the symposium by the institution of civil engineers and the reinforced concrete association, pp. 7-49. London, UK: Institution of Civil Engineers. 